\title{
Feasibility Study of Railway Line in Hilly Region using GIS
}

\author{
https://doi.org/10.3991/ijoe.v13i08.7186 \\ Yogesh Kumar ${ }^{(\varpi)}$ \\ SRM University, Delhi NCR Campus, India \\ Yogeshrajput07@gmail.com \\ Sandeep Panchal \\ NIT Hamirpur, Himachal Pradesh (H.P), India \\ Amit Ashish, Bhanu Pratap Singh \\ SRM University, Delhi NCR Campus, India
}

\begin{abstract}
Aim of this study is to demonstrate the potential of GIS and multi-criteria decision approach (MCDA) as a tool for the selection of alignment of rail route in Hilly region. In the present study, Geographic information system (GIS) and multi-criteria decision approach (MCDA) is used to plan the alignment of railway route from Bhuntar to Kullu in Himachal Pradesh (HP), India. The various factors which affect the alignment of rail route are identified in this study. The factors considered in this study are topography, land-use, distance from power line, drainage pattern and road network of the area. The Analytical Hierarchy Process (AHP) is used to determine the ranking of the relative parameters. The determined ranking is used in pair-wise comparison to find the weights of these relative parameters. The maps with weighted parameters are overlaid and resultant map is created in GIS for route finding, station location and alignment of railway. The final map shows the cumulative effect of all the factors which affect the rail route alignment. The final map is divided into four parts based on feasibility index. It is found that $55 \%$ area is highly feasible for route alignment while $25 \%$ of the total area comes under category of low feasibility.
\end{abstract}

Keywords-Geographic Information System (GIS), Multi-Criteria Decision Approach (MCDA), Digital Elevation Model (D.E.M), Analytical Hierarchy Process (AHP), Transportation Planning

\section{$1 \quad$ Introduction}

The population in the urban area is increasing abruptly. The rate of migration from the rural areas is increasing at exponential rate. Due to increasing urbanization, transportation system in urban areas is facing new challenges. Transportation planning in urban area has become complex because of modes involved, mixed traffic, multiple origins and multiple destinations. The task of adopting a particular route selection for 
transit systems is complex and challenging as it involves making decisions based on a large set of spatial dimensions (Sadek et al, 1999). Transportation agencies have been started to use Geographic Information Systems (GIS) technologies owing to the ability of GIS to manage data spatially in layers and then overlay these layers to perform spatial land-use suitability analyses (Namir et al; 2009).

GIS is widely used in different applications. Experience shows that GIS is an efficient tool for solving optimization tasks with spatially distributed linear objects such as railways, roads and pipelines. GIS is increasingly used in civil engineering applications. Transportation and highway engineering is one field which has been affected by developments in GIS aspects, as spatial variables, including environmental, topography, built-up areas, landuse/landcover and geology related variables, can be modeled easily (Mackenzie et al; 2009). These criteria are uncertain and unpredictable. Therefore, this complexity motivates transportation engineers to give more attention to GIS applications in route location and route alignment, due to their ability to consider many spatial variables simultaneously. Analyzing and understanding various parameters for of planning routes of transport communications is necessary to solve whole typical tasks. These parameters are related to evaluation of physiographic factor, landscape, engineering-geological and others requirements for the study area (Van Loon et al; 2011). These parameters also include determining the length of the route, calculation of intersections with rivers, roads which are considered as mountain relief complexities. Consideration of the railroad construction costs, which depends on geological structure (rocks, glacier, marshland etc.) and land-covers (forest, agriculture, builtup area etc.), and many others require detailed spatial multi-criteria analysis. In order to make proper decisions, the solutions of these complex problems require sequence of process for factors and criteria. These need to be processed to obtain relevant information.

The present study is an attempt for route planning using spatial analysis. The study area lies along NH-21 in Himachal Pradesh (H.P). The study area lies at longitude $77.1541 \mathrm{E}$ and latitude $31.8763 \mathrm{~N}$. The main assumption of this study is that the rail route will be along national highway. The proposed study area lies between longitude $76^{\circ} 54^{\prime} 55^{\prime \prime} \mathrm{E}$ to $77^{\circ} 06^{\prime} \mathrm{E}$ and $31^{\circ} 42^{\prime} 25^{\prime \prime} \mathrm{N}$ to $32^{\circ} 58^{\prime} \mathrm{N}$ latitude in H.P. The slope from Bhuntar to Kullu is $3 \%$ which is almost flat and permissible grade for laying route in study area. The total distance between Bhuntar to Kullu is $10.5 \mathrm{KM}$. The altitude of the district ranges from 1500 meter to 4800 meter from the mean sea level.

\section{$2 \quad$ Materials and methods}

The different type of maps and photographs are stored in the system. Then all the topo-sheets and scanned data is georeferenced to make a relationship of data in computer with the data on ground. The maps are scanned and stored in the system. All georeferenced data in the system is digitized. The various data is stored in the form of thematic layers in a single coordinate system. This data is analyzed (extraction, map overlay, conversion) using the spatial analyst tools. 


\subsection{Parameters of route feasibility}

Alignment and feasibility of rail route depends upon various factors like slope, distance from streams, distance from power line and land-use/land-cover. Conventional methods of rail route alignment are very complicated. The proximity to the city is an important parameter route planning and station locations. The station should be located at continent distance from the city for the continence of the passenger. In the present study, the proximity to Kullu city factor was developed as linear distance, such as developers want to see for the location of a rail station in a distance within $500 \mathrm{~m}$ and $3000 \mathrm{~m}$ from this city.

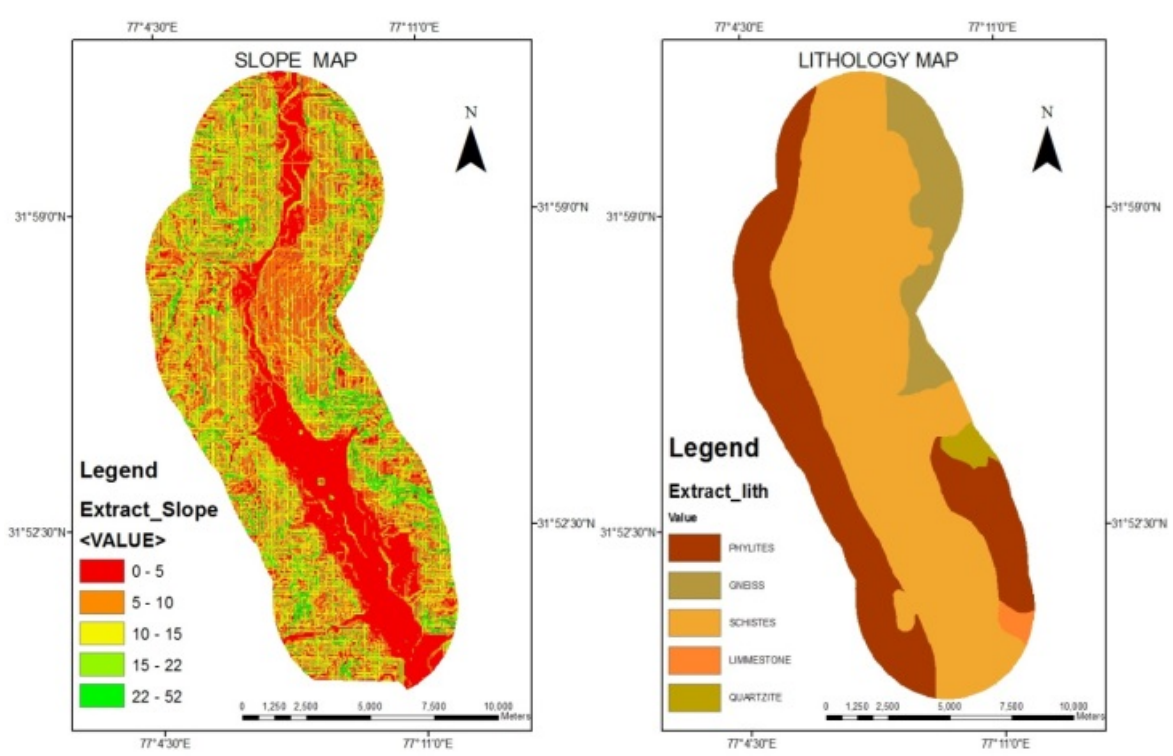

Fig. 1. Slope and Lithology Layer

Slope of the study area is a major factor which affects the economy of rail route and its alignment. High value of slope requires more cutting operation which proves to be uneconomical in the hilly regions. Slope of the study area is derived from a digital elevation model (DEM). The areas for rail station closer to roads were considered more suitable than those that are distant. The experts prefer to see a location for rail station within $30 \mathrm{~m}$ of roads as most suitable for cargo handling, the service of rail customers and also preferable for suitability within $500 \mathrm{~m}$ of roads.

Power is an essential requirement for running a metro rail. Power lines are also necessary for rail station and allocation. So, proximity to power line is considered in the study. Rail station in areas closer to existing power lines are more suitable than areas in distant. The areas that are affected by the ill effects of the water or the moisture are considered is inconvenient for construction. According rules of construction, any constructions should be is preferred in distance $300 \mathrm{~m}$ from water storage and 
$100 \mathrm{~m}$ from rivers that are expressed as a suitable. Experts gives the desirable result for the environmentalists and construction experts that require being at least $150 \mathrm{~m}$ and would be good if a distance of $1000 \mathrm{~m}$ was used. The alignment of the rail route depends on the suitability of the land-use of the study area.

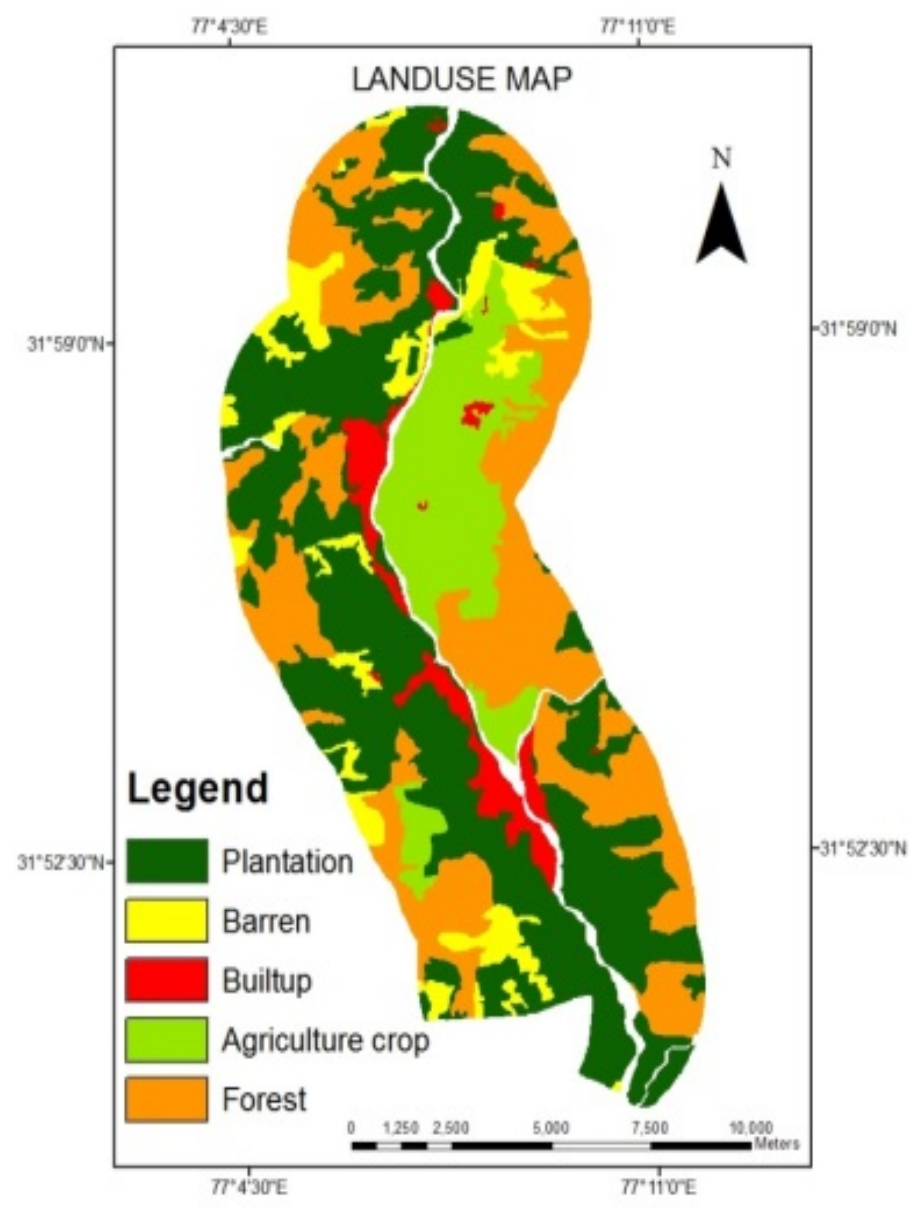

Fig. 2. Land-use/Land-cover Layer

Land-use map is downloaded from NRSC site which is combination of layers where the criteria given for land cover, forest, settlements. This is more important because construction of a rail station that damage and influence to agricultural and irrigated areas. The distance between railways stations and settlements should be greater than $100 \mathrm{~m}$. So, the areas of land within $100 \mathrm{~m}$ of settlements are considered as unsuitable. The different land-use classes were used to present the different terrains over the area of study and these was used in the final judgment for the best route path selection. 


\subsection{Methodology}

The geospatial tools with various evaluated criteria of parameter and effecting alignment are being used for metro rail feasibility. Various parameters are considered like; Topography, Geometrical, Environmental and geological for multi-criteria evaluation to select the best alignment and feasibility route of metro rail. A Digital Elevation Model (D.E.M), of the study area is used to find the slope map of the area of study.

The Analytical Hierarchy Process (AHP) is used to determine the ranking of the relative parameters and determine ranking are being used in pair-wise comparison to find the weight of criteria maps of these relative parameters (Saaty; 1980). These weighted criteria maps are overlaid and resultant map is created in GIS for grade and alignment purpose of metro rail. The combination of GIS capabilities with MCDM techniques provides the decision maker with support in all stages of decision making.

\subsection{Multi-criteria decision approach}

The information required depends on the nature of a spatial decision problem. There are several characteristics of spatial decision problems which are evaluated on the basis of multiple criteria. The spatial multi-criteria decision making (SMCDM) involves evaluation of geographical events based on criterion values and the decision maker's preferences to a set of evaluation criteria. The large number of factors causes difficulties in making spatial decisions, difficulties in attempting to acquire and process data to obtain information for making decisions. Therefore, using GIS and MCDM techniques to support the decision maker achieves greater effectiveness and efficiency of solving spatial decision problems.

The analytical hierarchy process (AHP) method, developed by Saaty (1980), is a Mathematical method for analyzing complex decisions with multiple criteria. The multi-criteria Decision uses hierarchical structures to represent a decision problem, and then develops Priorities for the alternatives based on the decision maker's judgments throughout the system. Its special value to managers is that it can be used to incorporate judgments on criteria. The most important aspect of the AHP is Pair wise comparisons used when quantitative ratings are cannot be used. Saaty presented a consistent way of finding the relative priority of each of the criteria from pair - wise comparisons. Table 1 shows the relative comparison matrix of various parameters.

Consistency ratio should not be more than $10 \%$ for a consistent solution. Thus the weights for criteria selected are found to be consistent. The pair-wise comparison matrixes for sub-criteria of these parameters are formed in same manner. These matrixes are shown on next pages. The consistency ratio is restricted to $10 \%$ and consistent solutions are found out. It is seen from the pair-wise comparison matrices that the land-use has highest value of weight and it is considered the most important factor that is responsible for rail route in the area. Slope and drainage also have significant effect on route feasibility. 
Table 1. Pair-wise comparison matrix

\begin{tabular}{|l|c|c|c|c|c|c|}
\hline \multicolumn{1}{|c|}{ Factors } & Landuse & Slope & Road & Drainage & Power-line & Geology \\
\hline Land-use & 1 & 2 & 3 & 5 & 7 & 9 \\
\hline Slope & 0.50 & 1 & 3 & 5 & 5 & 7 \\
\hline Road & 0.33 & 0.33 & 1 & 3 & 3 & 5 \\
\hline Drainage & 0.20 & 0.20 & 0.33 & 1 & 2 & 5 \\
\hline Power-line & 0.14 & 0.20 & 0.33 & 0.50 & 1 & 6 \\
\hline Geology & 0.11 & 0.14 & 0.20 & 0.20 & 0.17 & 1 \\
\hline Consistency Ratio & \multicolumn{7}{|c|}{$7.3 \%$} & & \\
\hline
\end{tabular}

Table 2. Pair-wise comparison matrix for proximity to city

\begin{tabular}{|c|c|c|c|c|c|}
\hline Sub-criteria(m) & $\mathbf{0 - 2 5 0}$ & $\mathbf{2 5 0 - 5 0 0}$ & $\mathbf{5 0 0 - 7 5 0}$ & $\mathbf{> 7 5 0}$ & Weights \% \\
\hline $0-250$ & 1 & 2 & 5 & 6 & 50.6 \\
\hline $250-500$ & 0.50 & 1 & 3 & 6 & 30.8 \\
\hline $500-750$ & 0.20 & 0.33 & 1 & 4 & 13.2 \\
\hline$>750$ & 0.17 & 0.7 & 0.25 & 1 & 5.3 \\
\hline \multicolumn{7}{|c|}{$\mathrm{CR}=5.7 \%$} \\
\hline
\end{tabular}

Table 3. Pair-wise comparison matrix for slope

\begin{tabular}{|c|c|c|c|c|c|c|}
\hline Sub-Criteria (\%) & $\mathbf{2 - 5} \%$ & $\mathbf{5 - 9} \%$ & $\mathbf{9 - 1 8 \%}$ & $\mathbf{1 8 - 2 7 \%}$ & $\mathbf{2 7 - 5 2 \%}$ & Weights \% \\
\hline $2-5 \%$ & 1 & 2 & 3 & 5 & 9 & 42.8 \\
\hline $5-9 \%$ & 0.50 & 1 & 2 & 5 & 7 & 28.8 \\
\hline $9-18 \%$ & 0.33 & 0.50 & 1 & 3 & 4 & 16.2 \\
\hline $18-27 \%$ & 0.20 & 0.20 & 0.33 & 1 & 5 & 8.7 \\
\hline $27-52 \%$ & 0.11 & 0.14 & 0.25 & 0.20 & 1 & 3.5 \\
\hline \multicolumn{7}{|c|}{ CR $=5.2 \%$} \\
\hline
\end{tabular}

Table 4. Pair-wise Comparison Matrix for Proximity to Road

\begin{tabular}{|c|c|c|c|c|c|c|}
\hline Sub criteria (m) & $\mathbf{3 0 - 5 0}$ & $\mathbf{5 0 - 1 0 0}$ & $\mathbf{1 0 0 - 3 0 0}$ & $\mathbf{3 0 0 - 5 0 0}$ & $>\mathbf{5 0 0}$ & Weights (\%) \\
\hline $30-50$ & 1 & 2 & 3 & 5 & 9 & 43.1 \\
\hline $50-100$ & 0.50 & 1 & 2 & 4 & 6 & 26.8 \\
\hline $100-300$ & 0.33 & 0.50 & 1 & 3 & 6 & 17.7 \\
\hline $300-500$ & 0.20 & 0.25 & 0.33 & 1 & 5 & 9.0 \\
\hline$>500$ & 0.11 & 0.17 & 0.17 & 0.20 & 1 & 3.0 \\
\hline \multicolumn{7}{|c|}{$\mathrm{CR}=4.7 \%$} \\
\hline
\end{tabular}


Table 5. Pair-wise comparison matrix for distance from drainage

\begin{tabular}{|c|c|c|c|c|c|c|}
\hline Sub criteria (m) & $\mathbf{2 0 0 0 - 1 5 0 0}$ & $\mathbf{1 5 0 0 - 1 2 0 0}$ & $\mathbf{1 2 0 0 - 8 0 0}$ & $\mathbf{8 0 0 - 5 0 0}$ & $\mathbf{5 0 0 - 2 0 0}$ & Weights (\%) \\
\hline $2000-1500$ & 1 & 2 & 4 & 6 & 9 & 45.0 \\
\hline $1500-1200$ & 0.50 & 1 & 3 & 5 & 7 & 29.5 \\
\hline $1200-800$ & 0.25 & 0.33 & 1 & 4 & 6 & 15.7 \\
\hline $800-500$ & 0.17 & 0.20 & 0.25 & 1 & 3 & 6.4 \\
\hline $500-200$ & 0.11 & 0.14 & 0.17 & 0.17 & 1 & 3.3 \\
\hline \multicolumn{7}{|c|}{ CR=5.5\% } \\
\hline
\end{tabular}

Table 6. Pair-wise comparison matrix for land-use/land-cover

\begin{tabular}{|c|c|c|c|c|c|c|}
\hline Sub-criteria (m) & Barren & Forest & Agriculture crop & Plantation & Built-up area & Weights \% \\
\hline Barren & 1 & 3 & 5 & 7 & 9 & 51.2 \\
\hline Forest & 0.33 & 1 & 2 & 6 & 8 & 25.5 \\
\hline Agriculture crop & 0.20 & 0.50 & 1 & 3 & 5 & 13.6 \\
\hline Plantation & 0.14 & 0.17 & 0.33 & 1 & 4 & 6.7 \\
\hline Built-up area & 0.11 & 0.12 & 0.20 & 0.25 & 1 & 3.1 \\
\hline \multicolumn{7}{|c}{ CR=6.3\% } \\
\hline
\end{tabular}

Table 7. Pair-wise comparison matrix for distance from transmission line

\begin{tabular}{|c|c|c|c|c|c|}
\hline Sub criteria (m) & $\mathbf{1 0 0 - 2 5 0}$ & $\mathbf{2 5 0 - 3 5 0}$ & $\mathbf{3 5 0 - 5 0 0}$ & $>\mathbf{5 0 0}$ & Weights (\%) \\
\hline $100-250$ & 1 & 3 & 6 & 9 & 60.2 \\
\hline $250-350$ & 0.33 & 1 & 2 & 5 & 22.3 \\
\hline $350-500$ & 0.17 & 0.50 & 1 & 4 & 12.9 \\
\hline$>500$ & 0.11 & 0.20 & 0.25 & 1 & 4.6 \\
\hline \multicolumn{7}{|c}{$\mathrm{CR}=3.4 \%$} \\
\hline
\end{tabular}

The weights of each criterion are calculated on the basis of analytic hierarchy process. These weights are assigned to the each layer. These layers are overlaid using weighted linear combination (WLC) techniques and a final map is created based upon feasibility index.

\section{$3 \quad$ Results and discussions}

Figure 4 shows the feasibility map of the study area. The feasibility map shows the feasibility of various parts of area towards rail route alignment. Feasibility index is a numerical index which is a combination of weightage of each criteria and sub-criteria. The map is re-classed on the basis of feasibility index to get a final map which shows the feasibility of the area for rail route. The feasibility map is divided into four criteria i.e. extremely feasible, highly feasible, moderately feasible and least feasible as shown in Fig. 4.

The rail route planning is a complicated process which depends upon the various factors which are uncertain in nature. The feasibility map is the result of the various 
factors considered in this study. The results of the study can be refined if more factors affecting the rail route are considered.

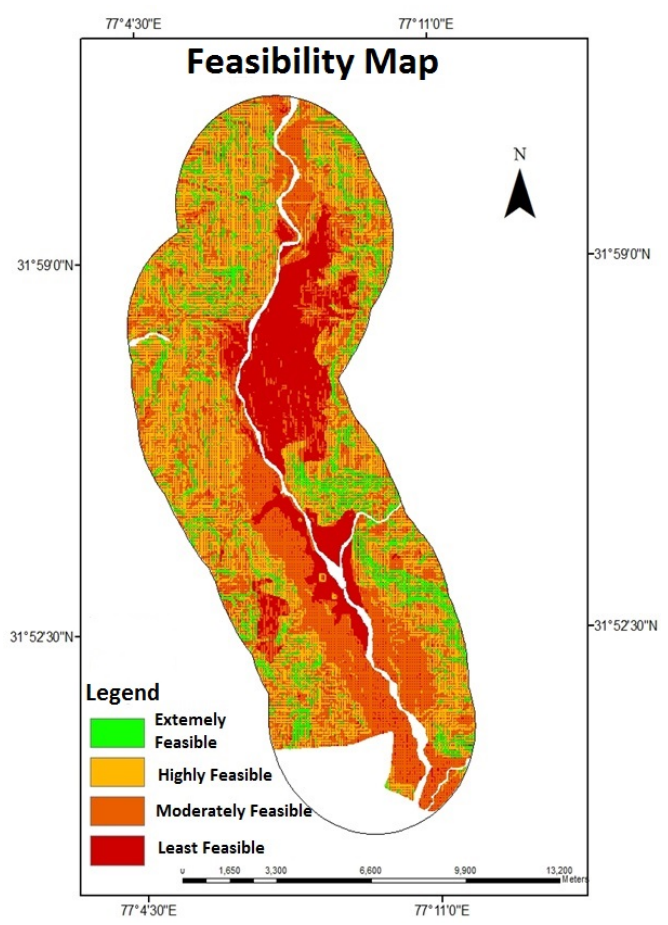

Fig.3. Feasibility map

\section{Conclusion}

The study shows the potential of GIS in rail route planning. It can be concluded that GIS can be used as a tool for rail route planning. The output of the study can be changed by varying the input. The input can be varied to change the output until the planner doesn't get satisfied. This study can be extended to least cost route and route optimization. The result of the study can be used by transportation system planners and road contractors.

\section{$5 \quad$ References}

[1] Sadek,S, Kaysi,Iand Bedran, M. (1998), .Geotechnical and Environmental Considerations in Highway Layout: An Integrated GIS Assessment Approach. ESRI User Conference.

[2] Dr. Namir G. Ahmed, Eng. Noor M. Asmael (2009). A GIS-assisted optimal route selection based on multi-criteria approach. The Iraqi Journal of Mechanical and Material Engineering, Special issue (D), pp. 556-567, 
[3] Mackenzie, W. and Cusworth, N.(2007). The Use and Abuse of Feasibility Studies. Melbourne". VIC, 19-20.

[4] Van Loon, R., Rietveld, P. and Martijn Brons, M. (2011). Travel-time reliability impacts on railway passenger demand: a revealed preference analysis", J. of Transport Geography. https://doi.org/10.1016/j.jtrangeo.2010.11.009

[5] Van Wee, B. (2007) .Large infrastructure projects: A review of the quality of demand forecasts and cost estimations." European J., Environment and Planning, 34(4), pp.-611625. https://doi.org/10.1068/b32110

[6] Magnussen, O.M. and Olsson, N(2006). Comparative analysis of cost estimates of major public investment projects.” Inter. J. of Project Management, 24, pp. - 281-288. https://doi.org/10.1016/j.ijproman.2005.11.011

[7] Bashar S. Al-Joboory, Maitham M. Al-Bakry and Oday Y. Al-Hamadany (2006). The Selection Of Optimum Road Path Using Geographic Information System (GIS). University of Baghdad, college of engineering, Department of Surveying, journal of Engineering Volume 12.

[8] Saaty T.L (1992). Multicriteria Decision Making - The Analytic Hierarchy Process", Volume 1 of the AHP Series, University of Pittsburgh.

[9] Q. J. Xiang, Y. F. Ma, and J. Lu (2007). Optimal Route Selection in Highway Network Based on Travel Decision Making. Proceedings of the IEEE Intelligent Vehicles Symposium Istanbul, Turkey. https://doi.org/10.1109/IVS.2007.4290292

[10] Saaty, T.L (1980). The Analytic Hierarchy Process. McGraw Hill, New York.

[11] Keiron, B(2003). AMIS: Development of a GIS/ Multicriteria Corridor Planning Methodology. Department of Geography and Regional Development, University of Arizona, Tucson, USA.

[12] Kobari, F(2000). Developing a Safety Management Tool Using a Geographic Information Systems (GIS)", Master thesis, An-Najah National University, Nablus, Palestine.

[13] Doleh, R. (2000). The Use of Traffic Assessment Modeling Technique in Evaluating and Testing Transportation Policies and Projects" Master thesis, An-Najah National University, Nablus, Palestine.

[14] AkjolDjenaliev(2007). Multicriteria decision making and GIS for railroad planning in Kyrgyzstan. Masters of Science Thesis in Geo-informatics,School of Architecture and the Built Environment, Royal Institute of Technology (KTH) ,Stockholm, Sweden.

\section{Authors}

Yogesh Kumar (corresponding author) is currently working as Assistant Professor at SRM University Delhi NCR campus, India. His specialization is Transportation Systems Engineering.

Sandeep Panchal is currently working as lecturer at National Institute of Technology, Hamirpur in India. His research interests are transportation planning, pavement materials and GIS applications in transportation systems.

Amit Ashish is currently working as Assistant Professor at SRM University Delhi NCR campus, India. His specialization is Environmental Engineering.

Bhanu Pratap is currently working as Assistant Professor at SRM University Delhi NCR campus, India. His specialization is Environmental Engineering.

Article submitted 21 May 2017. Published as resubmitted by the authors 26 June 2017. 